\title{
Clínicas do Testemunho: a política de reparação psíquica no Brasil
}

\author{
Alexei Conte Indursky \\ Universidade Paris VII \\ Daniela Sevegnani Mayorca \\ Universidade Federal de Minas Gerais
}

\section{Introdução}

O presente escrito propõe-se a discutir a emergência e implementação da política de reparação psíquica, Clínicas do Testemunho, na agenda de justiça de transição no Brasil. Promovido pela Comissão de Anistia/Ministério da Justiça entre os anos de 2013 e 2017, o Clínicas do Testemunho possuiu duas edições, realizadas através de convênios com instituições da sociedade civil dos estados do Rio de Janeiro, São Paulo, Rio Grande do Sul, Santa Catarina e Pernambuco, nas quais desenvolveu dispositivos clínico-políticos de atendimento individual e coletivo aos afetados pela ditadura civil-militar no Brasil (1964-1985). Nossa proposta neste artigo é ler o Clínicas do Testemunho dentro de um segundo tempo das políticas de reparação propostas pelo Estado brasileiro, debruçando-nos sobre a construção de uma metodologia psicanalítica de escuta dos efeitos da Violência de Estado. Nesse sentido, interessa-nos discutir como políticas de reparação psíquica como esta podem engendrar novas formas de reconhecimento aos afetados pela violência de Estado.

Para tanto, realizaremos uma breve recapitulação histórica sobre as condições de possibilidade de emergência do Clínicas do Testemunho. É importante ressaltar desde já que a demanda por reparação psíquica nunca figurou entre as "bandeiras" por Verdade, Memória e Justiça no Brasil. Traço que se revelará importante para entender, primeiro, a relação entre a oferta dessa política por parte do Estado e a sua recepção pela sociedade civil e, segundo, a resistência em absorver os efeitos dessa política dentro da agenda da justiça de transição.

Enquanto projeto inédito de reparação psíquica no Brasil, o Clínicas do Testemunho viu-se frente à necessidade de construir uma metodologia própria aos contextos de repressão em cada estado, tendo como base comum os pressupostos norteadores desta política. Almejamos demonstrar como os efeitos sintomáticos de um primeiro tempo da justiça de transição no Brasil foram determinantes para nossa leitura e elaboração dos dispositivos. Serão três as noções que nos servirão de fil rouge a esse percurso: trauma, silenciamento e testemunho. Noções incontornáveis para embasar uma compreensão psicanalítica de como os crimes perpetrados na ditadura civil-militar constituem-se como crimes de lesa-humanidade, cujos efeitos não lesam apenas aqueles que os sofreram diretamente, mas operam na destruição do tecido constitutivo da cultura.

Por fim, concluiremos com alguns apontamentos sobre possíveis efeitos do Clínicas do Testemunho frente à agenda da justiça de transição no Brasil. 


\section{Gramáticas de reconhecimento social: uma leitura psicossocial dos efeitos da agenda da justiça de transição no Brasil}

A fim de compreendermos a emergência da política de reparação psíquica, Clínicas do Testemunho, realizaremos uma leitura de como as várias políticas de reparação no Brasil engendraram uma complexa gramática de reconhecimento social acerca dos sujeitos afetados pela violência de Estado na ditadura. Para os antropólogos franceses Didier Fassin e Richard Rechtman (2007) as gramáticas de reconhecimento social, para além de seu apelo à justiça, estão sempre permeadas por uma “economia moral", em que os sentidos da condição de ser vítima estão em constante processo de negociação e disputa. Isto é, uma gramática de reconhecimento não se contenta em descrever o dano, reconhecer a vítima e estipular uma reparação, mas através de seu corpo discursivo ela produz performaticamente uma economia moral que passa a agenciar os sentidos do que é ser vítima.

É atentando aos efeitos dessa economia moral que Judith Butler (2003) aponta às crises de legitimação que o reconhecimento estatal pode produzir:

Esta crise de legitimação pode ser pensada a partir de várias perspectivas, mas consideremos, no momento, a dádiva ambivalente na qual a legitimação pode se transformar. Ser legitimado pelo Estado é aceitar os termos de legitimação oferecidos e descobrir que o senso público e reconhecível da pessoalidade é fundamentalmente dependente do léxico dessa legitimação. Dessa forma, a delimitação da legitimação ocorrerá somente através de uma exclusão de um certo tipo, embora não evidentemente dialética (Butler, 2003, p. 226).

Se as considerações de Butler nos lembram do efeito performativo que tais gramáticas produzem nos sujeitos, ressaltemos igualmente que a condição de vítima não é um topos o qual se ocupa de forma passiva. Aliás, muitas vezes ela sequer é reclamada enquanto tal pelos sujeitos em questão, mas é, invariavelmente, um espaço jurídico, político e psíquico ao qual se é confrontado a fim de ser reconhecido e, portanto, uma zona de constantes disputas e crises de legitimação e justificação. Nesse sentido, o que nos preocupa aqui é demonstrar como o campo da justiça de transição no Brasil acabou por engendrar uma gramática sintomática de reconhecimento social, em que a condição de vítima acabou ocupando espaços paradoxais e conflitivos frente ao Estado violador.

De acordo com Abrão e Torely (2010), nossa justiça de transição pode ser distinguida analiticamente em dois tempos. Num primeiro tempo, que abarca da Lei de Anistia de 1979 até 2007, teríamos uma política do esquecimento e da reconciliação, voltada exclusivamente à reparação financeira e individual, em que a Comissão de Anistia criada em 2002, limitava-se a receber e julgar processos administrativos de indenização. Num segundo tempo, a partir da criação de políticas de memória e reparação simbólica, Marcas da Memória e Caravanas de Anistia, o sentidos da anistia começam a conhecer uma importante inflexão em que o Estado passa a pedir perdão pelos atos de violência contra seus cidadãos, iniciando um intenso trabalho de memória e redefinição dos sentidos de ser afetado pela violência de Estado. É nesse segundo tempo que o Clínicas do Testemunho emerge inaugurando uma nova forma de reparação e, quiçá, de reconhecimento estatal, hipótese a ser desenvolvida ao longo deste escrito.

Os sentidos da anistia no Brasil possuem uma noção ambígua, inacabada e em plena disputa social. Se por um lado, a Lei de Anistia 6.683/79 procurou dar um ponto final às perseguições políticas 
realizadas pelos agentes do Estado, anistiando igualmente os perseguidos e exilados políticos do regime e os agentes públicos de repressão, por outro, seu texto equiparou os crimes destes agentes aos movimentos de resistência, através do artifício jurídico dos crimes conexos, procurando criar um consenso na opinião pública acerca da necessidade do perdão mútuo e de "página virada" em um país que viveu 21 anos de arbítrio, mortes e desaparecimentos forçados. No entanto, seria o caso de nos perguntarmos por que a lei de Anistia, aprovada por um senado biônico, sugeria no espírito de sua lei a necessidade de virar a página, de esquecer o passado, entrando em consonância assim com o discurso de boa parte dos militares e das oligarquias, que alegavam que no Brasil não houvera uma ditadura, mas uma "ditabranda", devido ao "relativo" baixo número de mortos e desaparecidos quando comparado às ditaduras de segurança nacional em outros países da América Latina1?

Pois, lembremos que na acepção grega da palavra anistia (amnestia) não há a noção de perdão, mas anamnesis (reminiscência) e amnesia (esquecimento). Ou seja, a presença da noção do perdão implantou-se como um vírus na letra da lei de Anistia, associando deliberadamente a ideia de perdão a de esquecimento.

No entanto, como a psicanálise nos lembra, para que haja a possibilidade do esquecimento, ou do trabalho de luto, é necessária a realização de anmnesis, isto é, do reconhecimento do traço que resta de um evento ou daquilo que foi perdido. O resultado dessa impossibilidade de reconhecer o traço da perda é a não-elaboração do passado, que tende a ser repetido indefinidamente no presente. Ora, nesse sentido: “[...] a anistia é o contrário do perdão, o qual [...] requer a memória" (Ricouer, 1995, p. 205-206), a verdade e a justiça. Dito de outra forma, não há como o Estado estabelecer uma política do perdão sem identificar quem perdoa, o quê e a quem.

Foi como reação a essa gramática de um "perdão sem reconhecimento" que foram criadas a Comissão Especial sobre Mortos e Desaparecidos Políticos (Lei 9.140) em 1995 e a Comissão de Anistia (Lei 10.559) em 2002. O principal objetivo da primeira é reconhecer a existência de cidadãos mortos e desaparecidos por motivações políticas independente de processos judiciais, bem como a análise dos pedidos de reparação financeira aos familiares. Em 2007, ela publicou um relatório onde aponta a existência de aproximadamente 400 mortos e desaparecidos pela ditadura. Já a Comissão de Anistia veio ampliar o escopo de atuação da comissão anterior, estendendo-o a torturas, prisões, exílios, demissões arbitrárias, cassações, e declarando a condição de anistiado político àqueles atingidos por esses atos.

No entanto, mesmo que ambas tenham sido conquistas importantes para demarcar a dívida do Estado brasileiro junto aos cidadãos afetados pela ditadura, a forma de reconhecimento das vítimas, nesse primeiro tempo da justiça de transição no Brasil, se manteve atrelada à unidimensionalidade da reparação financeira. Não entraremos aqui na discussão acerca do cálculo da reparação, nem do valor das indenizações e seus critérios, que viraram terreno de disputa entre os requerentes e a sociedade civil, ao acusarem a relação direta entre a notoriedade pública dos requerentes e o montante de suas reparações. O que nos interessa assinalar, para além dessas querelas, são os efeitos sociais, políticos e subjetivos que essa estreita gramática do reconhecimento engendrou nos sujeitos afetados e no tecido social.

\footnotetext{
${ }^{1}$ Argumento sustentado pela teoria dos dois demônios, que veiculada na Argentina, pretendia igualar as forças do Estado à força daqueles que resistiam à ilegitimidade da ditadura. Ver Bauer (2012).
} 
Um primeiro efeito importante a ser ressaltado foi o de colocar o sujeito que sofreu a violência de Estado na posição paradoxal de ser julgado pelo Estado que o violou. Isto é, criara-se no Brasil, à revelia das bandeira por memória, verdade e justiça, um processo de reconhecimento no qual, a fim de ser reconhecido pelo Estado, o sujeito deveria provar sua condição de vítima, recaindo sobre ele o ônus da prova. Não há como nos furtarmos de perguntar sobre os efeitos psíquicos e sociais de ter-se encontrado numa posição de sujeição ao Outro totalitário para, após anos de silenciamento e desmentido estatal, passar a ser investido pelo Estado numa posição ambivalente de sujeito de direitos e alvo de suspeitas. Ao ocupar essa posição, a palavra do sujeito é invariavelmente capturada por uma série de dispositivos que o colocam ora no lugar do herói da resistência, ora no lugar daquele que precisa provar sua sevícia, a fim de ser julgado pelos crimes que o Estado cometeu.

Um segundo efeito, decorrente direto desse primeiro, foi a produção narrativa de testemunhos centrados na prova jurídica, ou seja, uma forma do sujeito narrar suas histórias pautada pelo imperativo jurídico de apresentar provas que pudessem sustentar materialmente as violências que ele alegava ter sofrido. Em muitos casos, a produção dessas provas encontrava-se aquém da condição narrativa desses sujeitos. Colocar ao sujeito que sofreu a violência a tarefa de prová-la é reforçar, no subtexto, a tese das práticas tortura, a de que a vítima é a verdadeira responsável pelo que lhe aconteceu: "Será quebrado por dentro, pois sabemos fazer as coisas sem deixar marcas visíveis. Se sobreviver, jamais esquecerá o preço da sua valentia" diz o torturador (Sironi, 2010, p. 47). Ao exigir que o sujeito retorne a um lugar de desumanização para provar que ela foi real, a política pública acaba por fazê-lo voltar "sempre a esse tempo zero de sua vida: aquele a partir do qual eles se tornara um outro", o tempo da tortura (Sironi, 2010, p. 65).

Por fim, destacamos um terceiro efeito dessa política. A criação de uma falsa dicotomia de que a disputa pelos sentidos da anistia travava-se na luta entre "militares versus comunistas", endossando novamente a teoria dos dois demônios. Na medida em que para ser anistiado o sujeito deveria passar por um processo de veridicção, a fim de provar que fora vítima de atos de exceção, milhares de outros afetados - que não se encaixavam nestes termos, nem eram portadores de provas ou de legitimidade social para falarem e serem escutados a partir do lugar de afetado pela ditadura - passaram anos ausentes do debate público sobre a anistia no Brasil. Produzia-se assim uma economia moral em que a anistia do Estado não engendrava nos sujeitos efeitos produtivos de reconhecimento (Dunker, 2015), mas denunciava a sua borda perversa de poder ao criar uma falsa dicotomia, eximindo-se de responsabilizar-se por esses efeitos. Lembremos novamente das considerações de Butler (2003) ao descrever a forma de violência simbólica realizada pelo Estado quando este define lógicas binárias de reconhecimento: "a operação dessa força de exclusão se coloca fora do campo de luta, como se não fosse parte do poder, como se não fosse um objeto para reflexão política" (Butler, 2003, p. 228).

O efeito dessa violência simbólica foi alcunhado de silenciamento e será abordado na seção seguinte. Compreender sua extensão psicossocial é de suma importância, visto que ele foi responsável por uma modulação testemunhal hegemônica, na qual quem está autorizado a falar sobre a ditadura são suas vítimas maiores: exilados, torturados, familiares de mortos e desaparecidos (os outrora chamados de "subversivos" e "comunistas"), invisibilizando o fato de que a violência de Estado sistematizada e materializada então afetou profundamente a vida inúmeros cidadãos brasileiros que não estavam necessariamente associados à luta armada ou a um ideário comunista.

É somente a partir de 2007 que as políticas de reparação no Brasil vivem uma série de transformações, tratadas aqui como o segundo tempo da justiça de transição. São criadas, através da 
Comissão de Anistia, as Caravanas de Anistia e o projeto Marcas da Memória. As Caravanas se propuseram a realizar os "julgamentos" de Anistia em diversas cidades do país, onde a dimensão coletiva e ritualística do ato de Anistia parecia redescobrir a efetividade performativa do campo simbólico da palavra; na qual a elocução do "perdão" produz efeitos performativos de possibilitar o enlaçamento da vivência do sujeito junto às comunidades dentro das quais ela foi forjada ${ }^{2}$. Já o Marcas da Memória se propôs a discutir a temática da ditadura com a sociedade através de diversos dispositivos (discussão de filmes, sistematização de testemunhos, promoção de filmes sobre a temática, etc.). Ainda que estas políticas procurassem remeter as questões da memória e da história às suas dimensões coletivas, elas não modificaram as portas de entrada para o reconhecimento do sujeito afetado pela Comissão de Anistia, mantendo seu caráter exclusivamente individual e centrado nas reparações financeiras.

Lembremos, por fim, que em 24 de novembro de 2010 o Brasil é julgado e condenado na Corte Interamericana de Direitos Humanos (CIDH) no Caso Gomes Lund e outros (Guerrilha do Araguaia) vs. Brasil. A CIDH examinou pela primeira vez um caso de grave violação de Direitos Humanos praticada no Brasil durante o regime militar e decidiu que a interpretação conferida à Lei de Anistia de 1979, que impede a investigação, julgamento e sanção dos responsáveis por tais violações, era incompatível com as obrigações assumidas pelo Brasil ao vincular-se à Convenção Interamericana sobre Direitos Humanos. Ainda em sua sentença, a Corte determina que o Brasil cumpra com o dever de reparação integral, lançando mão de uma política de reparação psíquica aos afetados pela violência ditatorial. Essa condenação revelou-se um fato fundamental para a emergência do Clínicas do Testemunho ${ }^{3}$.

Cabe ressaltar que a continuidade das políticas de reparação que seguiram este novo momento da justiça de transição no Brasil, a partir da condenação na CIDH, foram gravemente interrompidas desde o impeachment da presidenta Dilma Rousseff, em 2016. O projeto Clínicas do Testemunho, que já tinha a garantia de verbas para sua execução até o final do ano de 2017, não foi interrompido naquele momento. Porém, após fim da vigência deste edital nenhum outro foi lançado pelos governos que seguiram e o projeto foi encerrado completamente em 2017.

O resgate apresentado até aqui parece deixar claro que, para além de uma terapêutica individual a ser desenvolvida junto aos afetados pela ditadura, uma política de reparação integral precisa incidir precisamente nas gramáticas sintomáticas de reconhecimento social. Visto que os destinos do trauma projetam-se em nosso horizonte social em uma disputa constante sobre os sentidos de nossa memória individual, coletiva e histórica, o projeto Clínicas do Testemunho teve de confrontar-se com a tarefa de pensar como articular modalidades de narrativas, de recepção e de transmissão de testemunhos, no seio das quais os próprios sentidos de ser vítima de violência de Estado pudessem ser reparados permanentemente.

\footnotetext{
2 Ver o documentário "Eu me lembro" (2012), que relata trabalho das Caravanas de Anistia.

${ }^{3} \mathrm{Na}$ sentença a CIDH imputou ao Estado brasileiro a "obrigação de investigar os fatos, julgar e, se for o caso, punir os responsáveis" (CIDH, 2010, p. 94), explicitando que disponha que este não poderia "utilizar disposições de direito interno, como prescrição, coisa julgada, irretroatividade da lei penal e ne bis in idem, nem qualquer excludente de responsabilidade similar, para eximir-se de seu dever" (CIDH, 2010, p. 95). Com base nesta sentença a OAB protocolou no Supremo Tribunal Federal, uma Arguição de Descumprimento de Preceito Fundamental (ADPF 153) na qual questiona a anistia aos representantes do Estado e sugerindo a revisão da Lei de Anistia (6.683/79). Em 2010 o STF finalmente se manifestou contrário à revisão, contrariando assim a sentença da $\mathrm{CIDH}$.
} 


\section{Clínicas do Testemunho, pressupostos e orientadores éticos da reparação psíquica}

O projeto-piloto Clínicas do Testemunho surge, assim, em 2012, através de um edital público destinado a instituições da sociedade civil ${ }^{4}$. Ao realizar esse edital, a Comissão de Anistia assumia a responsabilidade do Estado em reparar os danos psicossociais causados por ele durante os anos de chumbo. Não obstante, ela compreendia igualmente que, muito embora fosse o Estado o agente violador desses sujeitos, essa política deveria ser realizada inicialmente por instituições clínicas da sociedade civil. Isso justificava-se não apenas pela qualificação destas nessa área, mas pela possibilidade de, investidas pelo Estado, ocuparem uma função mediadora, que permitiria construir uma interface entre esses sujeitos e o Estado, construção de possibilidades de endereçamento a ele, anteriormente abalados pela violência e pelos efeitos do primeiro momento das políticas de reparação no Brasil. Soma-se a isso a dificuldade de implementação de núcleos de atendimento do Clínicas do Testemunho em estruturas e serviços públicos do SUS, que não possuíam nem a experiência prévia, nem as condições estruturais necessárias para tanto. Ressaltamos, assim, que desde o projeto piloto, o Clínicas do Testemunho tinha como objetivo a geração e o acúmulo de experiências, saberes e insumos que servissem de sustentação para a criação de uma política pública permanente de reparação psicossocial dos efeitos da violência de Estado.

O projeto foi composto por três eixos de atuação: 1) Clínica, 2) Capacitação e 3) Produção de insumos. Para os fins do presente escrito, iremos trabalhar, fundamentalmente, os aspectos metodológicos do eixo clínico. Esta política de reparação psíquica contemplou sujeitos afetados pela violência das ditaduras de Estado no período (1946-1988), bem como seus filhos e netos. Ressaltemos que, inicialmente, os sujeitos que teriam direito a engajar-se no projeto seriam somente aqueles reconhecidos oficialmente pela Comissão de Anistia, isto é, os anistiados. No entanto, após reuniões entre a sociedade civil, a Comissão de Acompanhamento da Sociedade Civil (CASC), e a coordenação da Comissão de Anistia, essa compreensão foi modificada, passando a estender o direito de reparação a sujeitos em processo de reconhecimento (anistiandos) e a sujeitos que não desejam ser anistiados pelo governo, por não considerarem esse reconhecimento financeiro produtivo ou necessário.

\subsection{Silenciamento, trauma e dispositivos}

Após essa breve recapitulação histórica, não é de forma nenhuma surpreendente que ao iniciarmos a execução do projeto-piloto do Clínicas do Testemunho em 2013, diversos possíveis beneficiários se pusessem a interrogar a pertinência e a ética do projeto a ser desenvolvido. De forma resumida, destacamos três principais fontes de resistência ao engajamento nessa política: (1) a desconfiança generalizada sobre toda a política de reparação do Estado; (2) o medo de ser estigmatizado ou ter seu sofrimento patologizado; (3) as preocupações sobre o uso político que o Estado poderia fazer do

\footnotetext{
${ }^{4}$ O projeto piloto durou de 2013 a 2015 e foi composto por quatro instituições conveniadas com a Comissão de Anistia, a saber: Instituto Sedes Sapientiae de São Paulo, Instituto Projetos Terapêuticos de São Paulo, Instituto Projetos Terapêuticos do Rio de Janeiro e a Sigmund Freud Associação Psicanalítica de Porto Alegre. Na segunda edição (2016 a 2017), o Clínicas do Testemunho conta com cinco núcleos de atendimento: São Paulo (Margens Clínicas/ISER e Instituto Sedes Sapientae), Rio de Janeiro (Projeto Clínico-Político/ISER), Santa Catarina e Rio Grande do Sul (Instituto APPOA).
} 
projeto. Essas resistências nortearam nossa compreensão sobre a atualidade do silenciamento de nossa história e foram decisivas para compreensão de seus efeitos traumáticos no tecido social.

Tomando as proposições de Sandor Ferenczi (2010), o traumático não se restringe ao ato de violência vivido pelo sujeito, mas concerne igualmente o desmentido infligido pelo ambiente social, no não-reconhecimento de uma vivência de excesso. $O$ ato do desmentido seria assim um acontecimento traumático sem autorização para ser vivido enquanto tal: um episódio sem sujeito, onde a distinção entre os registros de interioridade e exterioridade permaneceria anulada. Os efeitos psíquicos do desmentido repercutem diretamente no nível do Eu do sujeito, na medida em que o episódio não cessa efetivamente de acontecer, não se torna uma lembrança como outras, mas sua presença se torna uma espécie de enclave psíquico: a percepção do vivido se inscreve no psiquismo, mas sem autorização de entrar na transitividade do campo simbólico para se ligar aos demais traços mnésicos.

As contribuições de Ferenczi ao campo do traumático permanecem atuais e profícuas até os dias de hoje. Ao não restringir a etiologia do traumático a um modelo bio-neuro-psicológico, o psicanalista húngaro sustenta que as dimensões sócio-políticas são constituintes das formas de emergência do trauma, precisamente no sentido que o campo social e político confere a um evento extremo. Nesse sentido, conforme lembra Maria Rita Kehl:

[...] se o trauma, por sua própria definição de real não simbolizado, produz efeitos sintomáticos de repetição, as tentativas de esquecer os eventos traumáticos coletivos resultam em sintoma social. Quando uma sociedade não consegue elaborar os efeitos de um trauma e opta por tentar apagar a memória do evento traumático, esse simulacro de recalque coletivo tende a produzir repetições sinistras (Kehl, 2010, p. $81)$.

Nesse sentido, transpondo as hipóteses ferenczianas ao nosso campo, propomos ler os efeitos da postura do Estado brasileiro sob a ótica do desmentido. Ao conceder Anistia sem reconhecer seus agentes e seus crimes, o primeiro tempo da justiça de transição no Brasil parece operar no laço social os mesmos efeitos de desmentido descobertos na clínica psicanalítica, reatualizando o sofrimento experimentado através da desautorização do seu reconhecimento social. O silenciamento pode ser definido, portanto, como um sintoma social frente às tentativas frustradas de simbolizar os atos de exceção ocorridos no Brasil que, por um lado, falharam em reconhecer, responsabilizar e punir seus agentes, e por outro, produziram efeitos improdutivos de reconhecimento (Dunker, 2015) junto às suas vítimas. Dito de outra forma, o silenciamento diz menos de uma ausência de testemunhos, do que de um "Silêncio dos outros"5 e do Outro estatal, na impossibilidade de escutar e reconhecer as narrativas de seus cidadãos.

Frente a esse desafio, propomos a criação de dispositivos que interpelassem esse silenciamento a partir da dimensão singular e coletiva de seus efeitos. Mas o que é um dispositivo? Como operá-lo frente a sintomas tão fortemente impetrados em nosso tecido social?

Tomemos aqui uma passagem em que o filósofo italiano Giorgio Agamben (2014) retoma a noção de dispositivo empregada por Michel Foucault. Se para o pensador francês o dispositivo

\footnotetext{
${ }^{5}$ Referência ao filme espanhol Silêncio dos outros que aborda a mesma problemática no contexto espanhol.
} 
implica um processo de subjetivação, sem o qual não há efeito de governamentalidade, Agamben sugere que os dispositivos em seu conjunto de práticas, discursos, leis e racionalidades passam a operar igualmente uma espécie de dessubjetivação, a partir do qual a potência do desejo e da política permanecem separadas do sujeito, seu corpo e suas práticas. Desta feita, segundo o filósofo italiano, a estratégia maior frente a tal efeito biopolítico seria a de profanar tais dispositivos, liberando aquilo que foi separado dos sujeitos, e restituí-los a um possível uso comum (Agamben, 2014).

Liamos assim a tarefa que se impunha ao Clínicas do Testemunho: profanar os efeitos de silenciamento engendrados, tanto pelas violências de Estado, quanto pelas políticas de reparação, demonstrando que esse silenciamento não carecia de testemunhos, mas, precisamente o inverso: que a potência dos testemunhos precisava ser restituída a nosso uso comum.

Dessa forma, criamos as Conversas e Audiências Públicas, em que os efeitos da violência de Estado eram debatidos e para quais eram sempre convidados representantes do poder público a ocupar o lugar de debatedores e, sobretudo, de receptores das falas ali proferidas. Para cada encontro elaborava-se uma temática específica a ser debatida, convidando pesquisadores, militantes, membros de organizações da sociedade civil e afetados pela violência para compor uma mesa, convocando em seguida o público para o debate.

Para ilustrar a construção desses dispositivos, detenhamo-nos numa Conversa Pública do Clínicas do Testemunho de Porto Alegre, cuja temática versou sobre os efeitos transgeracionais da violência de Estado. Como disparador da Conversa foi exibido o curta-metragem 15 filhos (1996) de Marta Nehring e Maria de Oliveira. Em uma dada cena do documentário, uma das filhas entrevistadas, Tessa Lacerda ${ }^{6}$, relata um momento de sua infância em que ela fora transferida para uma nova escola. Ao chegar no pátio do recreio, ela experimenta uma angústia que a impossibilita de permanecer ali. A direção da escola convoca sua mãe, Mariluce, a fim de conversarem sobre o comportamento da filha. Ao chegar no pátio da escola, Mariluce nota a forte semelhança entre a arquitetura da escola e a prisão em que vira pela última vez seu marido, na época, ainda grávida de Tessa. Ela comunica isso a filha, dando-lhe assim uma palavra, um nome com o qual circunscrever um afeto "enterrado" no inconsciente de sua filha que, desta feita, pôde dar figuração a um sofrimento que até então a habitava sem palavras, desautorizado de ser vivido enquanto tal.

Após a exibição do curta, um historiador toma a palavra, desde a plateia, para ressaltar a importância de termos uma política de reparação psíquica, sobretudo porque aqueles que trabalham com o tema também são profundamente afetados por ele. Ele confessa que uma série de imagens lhe invadiram ao ver o documentário, imagens do dia em que seu pai lhe obrigara a queimar os livros no fogão à lenha de sua casa no interior do Rio Grande do Sul. Ao terminar de contar a cena, ele acrescenta, "meu pai pediu para que eu nunca contasse quais os livros que tínhamos em casa". Essa cena ficara "enterrada" durante anos, sem direito de sítio em seu psiquismo; na verdade, nunca fora esquecida, mas tampouco havia sido compartilhada, encontrando-se, assim, silenciada. A cena do documentário parece ter servido de tela, isto é, de suporte sobre o qual o historiador pôde projetar a

\footnotetext{
${ }^{6}$ Filha de Gildo Macedo Lacerda e de Mariluce. Gildo e Mariluce foram presos, em outubro de 1973, em Salvador. Mariluce estava grávida de um mês. Quando se encontraram dentro da Superintendência da Polícia Federal, olharam-se angustiados e longamente; foram separados e nunca mais se viram. Gildo foi torturado até a morte, no dia 29, no DOICodi do Recife. Nota oficial anunciou sua morte, junto com a de José Carlos Novaes da Matta Machado, "por enfrentamento na rua". Com o nascimento de Tessa, 8 meses após a morte do pai, Mariluce travou incansável batalha judicial, que se arrastou por 18 anos, para que a paternidade de Gildo fosse reconhecida.
} 
sua cena desmentida. Enunciada em uma Conversa Pública, a potência dessa cena não reside tão somente no fator catártico que, por certo, ela engendrava tal como um contágio em todos os presentes. "Enterrada" como um pacto familiar, ao ser coletivizada, essa cena produz um efeito de profanação, restituindo ao público aquilo que havia sido capturado pela violência de Estado; ela tornava-se ali um testemunho.

\subsection{Políticas do Testemunho}

A noção de testemunho revelou-se norteadora desse dispositivo de escuta, na medida em que possui a particularidade de constituir-se na dobradiça entre o privado e o público, realizando assim um transbordamento bi-vetorial entre as esferas do subjetivo e do político. O efeito das Conversas Públicas permitiu, portanto, a inauguração de novos dispositivos clínicos, alcunhados de Grupos de Testemunho. A meio caminho entre o público e o privado, esses grupos constituíram-se como espaços intermediários, permitindo que as pessoas se aproximassem sem se sentirem expostas e prestar um testemunho em público.

Retornemos ao caso do historiador que falara na Conversa Pública citada acima. Ao apresentarse em um Grupo de Testemunho ele inicialmente passa a reproduzir sua função de historiador buscando registrar as reuniões que, num segundo momento, seriam transformadas em arquivos. Para além de sua postura de perito frente à tarefa do grupo, ele revelava surpreendentemente que não se reconhecia como vítima da ditadura. Gradualmente, sua participação no grupo o permite ressignificar o sentido do que é ser afetado, passando a construir o seu próprio testemunho, o que o leva a questionar-se sobre muitas das escolhas pessoais que havia feito ao longo de sua vida.

Em seu Vocabulário, Émile Benveniste (1995), define que tanto a noção testis, quanto superstes, ambas provenientes do sânscrito, remetem à condição de ser testemunha de um acontecimento. No entanto, a noção do testis coloca o sujeito enquanto um terceiro que vê a cena, ou seja, está marcada pela visão, à base do paradigma do direito positivista. Ao passo que a noção superstes, remeteria ao sujeito que participa da cena, que não possui uma visão dela, mas a audição, ou seja, um sobrevivente que, ao emergir da cena, pode narrá-la. Desta feita, o que diferencia o superstis do terstis para Benveniste não é somente o fato de presenciar o evento, mas o de "subsistir muito mais além desse acontecimento" (Benveniste, 1995, p. 174).

No campo do direito positivo, calcado na acepção de terstis, prestar um depoimento perante à justiça implica na busca pela verdade, isto é, falar a verdade, nada mais que a verdade. A figura da testemunha, na condição de álibi da verdade, é assim investida da necessidade de que, ao repetir seu depoimento, ela conte uma mesma história, relate a mesma cena, ateste da verdade que não conhecerá mudanças com o tempo. De forma geral, pode-se dizer que os testemunhos que encontrávamos no momento de implementação do Clínicas do Testemunho calcavam-se nessa acepção do testemunho, em que o testemunhante deveria necessariamente produzir com sua narrativa elementos que pudessem servir de prova jurídica. Esse imperativo por verdade, no entanto, não deixava de cobrar seus custos subjetivos aos sujeitos que, em meio a sessões de Comissões Estaduais ou da Comissão Nacional da Verdade, experimentaram momentos de "apagão", de "branco", em que não conseguiam nada lembrar. Nesses casos, o dever à memória parecia produzir uma espécie de injunção psíquica, em que um evento não simbolizado ou desautorizado em seu psiquismo, ao ser evocado pelo sujeito, acabava interrompendo sua cadeia associativa, sob o despertar de grande angústia. Não por acaso, o Clínicas 
do Testemunho foi convocado nos estado de São Paulo, Rio de Janeiro e Rio Grande do Sul a compor estratégias conjuntas às Comissões Estaduais da Verdade, a fim de preparar as sessões de testemunho e acompanhá-las antes, durante e depois, tamanho eram os efeitos de reatualização dos traumas experimentados nas sessões de oitiva.

Dentro dos Grupos de testemunhos, ao trabalharmos com uma dimensão processual e transitiva do testemunho, mais próxima a dimensão de surperstis descrita por Benveniste, descobria-se que na medida em que as condições sociais de recepção de um testemunho eram transformadas, o mesmo sujeito modificava a forma de narrar sua história. Por exemplo, sujeitos que produziram testemunhos extremamente centrados na demonstração da tortura, na produção da prova jurídica, passaram a poder desenvolver outros aspectos de sua memória e percursos de vida. Assim como, sujeitos que nunca haviam produzido testemunhos passam a dar-se conta dos pontos em comum com muitas narrativas.

A partir da experiência grupal, o dispositivo de Conversas Públicas passou a ser ressignificado pelos participantes dos Grupos de Testemunho. Ao constituírem seus testemunhos através da experiência grupal, muitos dos participantes demonstraram seu desejo de prestar pública e coletivamente seu testemunho de forma inédita. Do silenciamento ao protagonismo, o testemunho desses sujeitos foi marcado por novas formas de narrativas. Isto é, a medida em que as condições sociais de recepção e reconhecimento dos testemunhos eram possibilitadas, passamos a testemunhar a quebra de pactos de silêncio instituídos dentro de famílias, grupos e amigos.

\section{Efeitos da política de reparação psíquica}

O artista Oscar Muñoz, em trabalho intitulado Re-trato, propõe pensar desta forma o estatuto dos desaparecimentos forçados durante o conflito entre paramilitares, guerrilheiros e o governo colombiano: sob uma pedra cinza, o autor desenha com um pincel os rostos dos desaparecidos. No entanto, ao invés de tinta, o material utilizado para a inscrição dessa memória da violência é a água. Ou seja, concomitante ao tingimento do traço contra a superfície pétrea, há o seu gradual apagamento. O vídeo que expõe essa intervenção permanece, assim, regido por uma espécie de inacabamento intrínseco, no qual o ímpeto de finalizar o re-trato é ipsis literis sua sentença de recomeçá-lo. Daí o hífen que marca sua escrita, o prefixo "re-" conjuga o trabalho de recomeçar; ao mesmo tempo, enquanto condição de possibilidade de sua inscrição (só há traço na medida em que se apaga a marca), e seu caráter sempre inacabado em nossa memória coletiva. É a partir dessa dialética da imagem de Muñoz que propomos a avaliação da política do Clínicas do Testemunho.

\subsection{O que se repara?}

O termo "reparar" empregado no campo da justiça de transição é um verbo que precisa ser analisado em relação a seu objeto e métodos, isto é: O que se repara? Como se repara?

Reparar aqui não é o mesmo que restaurar, fazer retornar a um estado anterior ao dano, onde pretensamente se integrariam os fragmentos de um objeto dispersos por uma ruptura, como se tal ato de restituir-lhes um mesmo contorno pudesse lhes devolver o seu status quo ante, isto é, sua situação anterior. Assim como a experiência traumática, certamente, não pode ser restringida a um evento isolado de violência, uma política de reparação deve necessariamente apostar na articulação entre a 
impossibilidade de tudo representar do horror vivido e a necessidade de criar condições sociais de recepção e transmissão das memórias silenciadas dessa história.

Nesse sentido, o que se busca reparar é a história através da inscrição dos testemunhos antes dela foracluídos. Encontrar formas de fraturar "o chão duro da história, traumatizando-o" (Alves Lima, 2017, p. 128) com o testemunho daqueles que a viveram pelo avesso, no lado oposto ao dos vencedores, sob o peso das suas armas. Se no plano individual não ser capaz de representar e narrar sua história é estar condenado a repeti-la, assim também acontece no plano político. As experiências traumáticas de uma sociedade, silenciadas como experiências individuais, vagam em busca de escuta e arquivos que possam materializá-las. O que não pôde ser transformado em memória contada, em horror compartilhado, está destinado a vagar como fantasma à espera do próximo cadafalso da história para retornar uma vez mais.

Quanto ao seu método, a possibilidade de fazer reparação de memória coletiva passa pela possibilidade de desprivatizar a marca da violência testemunhada, uma vez que seu enunciado é também denúncia da catástrofe política e social de nossos tempos. Por isso é que o Clínicas do Testemunho distancia-se de uma busca pela verdade absoluta; a aposta repousa, antes, na oferta de uma escuta que testemunhe o horror vivido, uma que não se levanta quando o relato do terror se inicia, que permanece e acolhe a inscrição da narrativa possível do vivido. Desta feita, este ato clínicopolítico que se lança como testemunho, de um ao outro, permite a construção de redes que possibilitam a reparação do tecido social pela inscrição da vivência subjetiva em nossa história através da restauração da possibilidade de, a partir destas histórias, fazer laço, alvo primeiro da violência.

\subsection{Quebra do silenciamento e estratégias de regionalização}

Nesse sentido, na medida que os efeitos clínicos operam, a participação e o protagonismo dos participantes do projeto tornam-se um vetor de contra-irradiação do medo e do silenciamento. Ao observarem que o processo testemunhal não é danoso ou traumatogênico, familiares, amigos e demais pessoas começam a engajar-se na possibilidade de falar. Muitos foram os casos em que a entrada nos Grupos de Testemunho engendrou também a demanda por um tratamento individual. O processo grupal, em sua potência coletiva e identificatória, permite que através do compartilhamento das vivências o sujeito revisite suas lembranças e se coloque em outra posição frente à situação de violência, dor, vergonha, desumanização. Não raro, quando uma situação grupal opera esses deslocamentos, um espaço individual é demandado. No entanto, essa passagem do coletivo para o individual não implica que o atendimento individual seja o único destino para tais situações, mas a oferta de um lugar para se ressignificar tais vivências; sendo que a escolha de compartilhá-las será justamente um dos efeitos produzidos pelo tratamento.

Essa passagem do silenciamento ao protagonismo dos sujeitos engajados no projeto propiciou a implementação de estratégias de regionalização de Conversas Públicas e Capacitações em cidades do interior do Rio Grande do Sul e Santa Catarina, elencadas conforme a concentração de afetados e as parcerias com instituições do poder público, universidades e movimentos por MVJ da sociedade civil. Realizaram-se assim atividades em São Leopoldo, Novo Hamburgo, Santa Maria, Pelotas, Rio Grande, Caxias do Sul, Ijuí, Itajaí, Criciúma e Joinville. Em todas atividades, participantes do projeto prestaram seus testemunhos, contando com o apoio massivo da população. Destaca-se ainda a criação 
de Coletivo Nacional de Filhos e Netos de afetados, a partir da articulação de vários participantes dos Clínicas do Testemunho.

\subsection{Gramáticas de reconhecimento social}

Será sob essa perspectiva, portanto, que poderemos afirmar que na medida em que se incide nas relações sintomáticas entre Estado, sociedade civil e vítimas da ditadura as condições sociais de recepção do testemunho são transformadas, encontrando novas espacialidades para o sujeito traduzir o terror em experiências de resistência. Contudo, é importante sublinhar que o efeito dessa quebra do silenciamento não se limita a promover um lugar de fala para o que outrora encontrava-se silenciado e privatizado. Mas que há aí um efeito subjacente importante que toca precisamente na transformação das gramáticas de reconhecimento social destes testemunhos.

No que tange à porta de entrada ao direito à reparação, o Clínicas do Testemunho já difere, de partida, do processo administrativo de indenização da Comissão de Anistia. Como assinalamos acima, inicialmente a reparação psíquica iria destinar-se somente aos anistiados políticos pela Comissão de Anistia. No entanto, após discussões com os comissionados e com o CASC, foi demonstrada a importância de que outras vítimas pudessem recorrer a esse direito, visto que muitos abriram mão do direito à reparação financeira por considerá-la improdutiva (Dunker, 2015) e, muitas vezes, revitimizante. Estendeu-se assim o direito à reparação psíquica a todos os afetados pela violência da ditadura até sua terceira geração. Compreende-se assim que, ao ingressar no Clínicas do Testemunho, o Estado reconhecia que as violências da ditadura produziram nesse sujeito sofrimentos de ordem psíquica, moral e física, e que era sua responsabilidade repará-los.

Podemos pensar assim que, já de partida, a abertura do direito à reparação psíquica promoveu uma descentralização da forma de reconhecimento do Estado junto aos afetados pela ditadura, abrindo-se uma segunda porta (ainda que muitas vezes, ela seja considerada uma porta dos fundos) ao reconhecimento do Estado.

Para ser admitido no Clínicas do Testemunho, o usuário devia preencher uma ficha de inscrição, informando seus dados pessoais e o ato de exceção ao qual ele ou seu familiar fora exposto. No entanto, diferentemente do reconhecimento agenciado pelos processos de indenização, para que um sujeito pudesse ser atendido pelo Clínicas do Testemunho, ele não precisa passar por um dispositivo administrativo de veridicção estatal, a fim de ser reconhecido. A princípio, bastava que o ato de exceção ali descrito estivesse condizente com referências de data, cidade e aspectos gerais do crime para que ele fosse aceito no projeto. Cuidado realizado justamente para que a entrada de sujeito no projeto não atualizasse as políticas de suspeita e silenciamento de outrora.

Assim sendo, essa diferença na porta de entrada do Clínicas do Testemunho, operou uma modificação importante em que a primazia da prova do dano deslocou-se para a do desejo do sujeito em ser escutado e testemunhar. Essa modificação na porta de entrada do Clínicas do Testemunho permitiu que centenas de pessoas que nunca haviam sido reconhecidas pelo Estado brasileiro como vítimas da ditadura pudessem ser escutadas pela primeira vez sem um crivo moral ou jurídico que lhes obrigasse a atestar os fatos narrados. Nessa perspectiva, a produção de um testemunho é um efeito a posteriori da reparação, não uma condição para o engajamento nele.

No entanto, essa modificação promoveu igualmente novas tensões. A primeira, como esperado, foi a reatualização da suspeita Estatal, onde a entrada na política de reparação psíquica era vista como 
forma de pressão política de certos sujeitos que tinham tido seus processos de indenização indeferidos pela Comissão de Anistia. Esse foi efetivamente o caso de muitos militares que foram expulsos das Forças Armadas e, tendo seus processos de Anistia revisados pela AGU, vivem ainda hoje como párias em suas comunidades; ao mesmo tempo, execrados pelas Forças como traidores e por suas comunidades como torturadores ${ }^{7}$. Como já discutido anteriormente (Indursky e Kveller, 2018), em muitos desses casos foi possível trabalhar em Grupos de Testemunho um deslocamento importante da posição de reivindicação de indenização - calcado no paradigma jurídico - em direção a uma dimensão testemunhal, que produziu efeitos de saúde importantes para muitos desses sujeitos.

A segunda tensão importante sustentada pelo projeto, possibilitada por essa mudança nos paradigmas da gramática de reconhecimento social do que é ser vítima da ditadura civil-militar, foi a extensão da oferta de políticas de reparação a comunidades periféricas. Populações empobrecidas da cidade e do campo que nunca haviam sido reconhecidas como afetadas, precisamente pela sua naturalização, sem representatividade política para inscrever o impacto da violência de Estado em suas famílias e comunidades durante aquele período. Ali a violência estatal nunca pode ser nem nomeada como enquanto tal, nem delimitada no tempo, na marcação de um começo, um meio e um fim. As invasões, torturas, execuções e desaparecimentos aconteciam antes da ditadura, seguiram durante ela e foram ainda intensificadas depois do seu fim. Essa tensão, que não iremos explorar mais longamente aqui, nos leva ao terceiro efeito importante desta política de reparação.

\subsection{Reparação psíquica da violência de Estado na democracia}

A partir das tensões suscitadas pelo Clínicas do Testemunho, no final de 2016, os núcleos de atendimento identificaram a necessidade de estender as políticas de reparação até onde a violência de Estado seguia fazendo vítimas no presente. Através de uma parceria entre a Comissão de Anistia com o British Council, através do Newton Fund, foi possível viabilizar um programa de reparação espelhado no projeto Clínicas do Testemunho para a garantia do direito à reparação psíquica à violência de Estado no presente, entendida como um continuum da repressão ditatorial. Foram criadas clínicas de atendimento individual e em grupo para vítimas de graves violações de direitos humanos de diversos contextos, conversas públicas e cursos de capacitação aos profissionais da rede pública de atenção psicossocial. Assim surgiram os Centros de Estudos em Reparação Psíquica (CERP).

A experiência dos núcleos de trabalho do Clínicas do Testemunho serviu para fundar os CERPs baseados nas metodologias de reparação anteriormente desenvolvidas em cada estado. Assim fazendo os CERP serviram para unir em uma mesma aposta a necessidade de políticas de reparação para as violências do passado e do presente, alterando desta forma as gramáticas do reconhecimento social de ambos os grupos, possibilitando nomear a violência a partir de uma nova perspectiva histórica e também jurídica.

\footnotetext{
${ }^{7}$ A situação que os reuniu dizia respeito à polêmica em torno da Portaria 1.104, de outubro de 1964, que previa o fim da estabilidade e o desligamento de cabos que atingissem o período de oito anos sem alcançar outra graduação. Inicialmente esta portaria foi configurada como ato de exceção, e os cabos atingidos considerados aptos a receber a anistia. Em 2014, uma série de pareceres jurídicos produzidos pelo Ministério da Justiça e da Advocacia Geral da União (AGU) embasou a decisão de retirar a concessão de anistia concedida a 495 ex-cabos da Aeronáutica. A partir de 2011, um novo grupo de trabalho interministerial foi criado para revisar 2.574 destes processos.
} 


\section{Considerações finais}

O presente escrito propõe-se a discutir a emergência e implementação da política de reparação psíquica, Clínicas do Testemunho, na agenda de justiça de transição no Brasil. Promovido pela Comissão de Anistia/Ministério da Justiça entre os anos de 2013 e 2017.

À guisa de conclusão, ressaltamos que os efeitos psicossociais da política de reparação do Clínicas do Testemunho devem ser concebidos inicialmente pelo impacto simbólico de sua implementação junto à sociedade brasileira, nomeado aqui sob a insígnia da quebra do silenciamento. A partir dos elementos apresentados acima, sustentamos que, a partir das duas edições do Clínicas do Testemunho, realizou-se uma modificação no estatuto do testemunho para os diversos atores da justiça de transição no Brasil. Desde o enclausuramento das narrativas do terror ao campo individual dos afetados para a sua inscrição no corpo social como elementos fundamentais para a construção de um país verdadeiramente democrático.

Cabe ressaltar que a recusa em relembrar não veio dos afetados pela repressão ditatorial, isto se evidencia na quantidade de livros, documentários, blogs que os afetados produziram ao longo destes anos numa tentativa de contar e fazer marca com suas experiências. A recusa em escutar, o desejo de ver desaparecer as desagradáveis lembranças daquele período veio por um lado das instituições que, em nome de uma "transição lenta, gradual e segura", mantiveram intactas diversas estruturas, atores e práticas do autoritarismo; pelo Estado em sua recusa insistente em escutar estes relatos e por outro, da sociedade civil que, vacinada pelo medo, ignorou as histórias de horror que colegas, familiares e amigos guardavam e optaram uma e outra vez pelo silenciamento.

O longo período de silenciamento, a ausência de julgamento e responsabilização dos agentes da repressão, a individualização dos processos de reparação e o desmentido da memória que operaram nestes anos e seguem ressoando nas políticas atuais, causando danos verdadeiramente irreparáveis no tecido social. A impossibilidade de fazer do Clínicas do Testemunho uma política de Estado permanente como era seu objetivo inicial e a incapacidade de fazer da ditadura uma experiência coletiva de horror nos coloca diante de uma constante ameaça de repetição do autoritarismo e da consequente oferta da violência como solução para os conflitos sociais.

O Clínicas do Testemunho mostrou como é possível encarar a responsabilidade Estatal pelas violações de ontem e de hoje, fazendo emergir a palavra-testemunho como antídoto para os efeitos da violência. Contra a repetição do autoritarismo que se antecipa, em suas sempre renovadas formas, será preciso, ainda, buscar tantas outras brechas para a emergência das palavras.

\section{Referências}

15 FILHOS. Direção: OLIVEIRA, Maria; NEHRING, Marta. São Paulo: Sinapse, 1996. DVD (20 $\min )$.

ABRÃO, Paulo; TORELLY, Marcelo D. As dimensões da Justiça de Transição no Brasil, a eficácia da Lei de Anistia e as alternativas para a verdade e a justiça. In: A anistia na era da responsabilização: o Brasil em perspectiva internacional e comparada. Brasília/Oxford: Ministério da Justiça, Comissão de Anistia/Oxford University, Latin American Centre, 2011. 
AGAMBEN, Giorgio. O amigo \& O que é um dispositivo. Chapecó: Argos, 2014.

ALVES LIMA, Rafael. Análise Reparável e Irreparável: o Conceito Psicanalítico de Reparação na Agenda da Transição Brasileira. Psicologia: Ciência e Profissão, v. 37, p.116-132, 2017.

BAUER, Caroline. Brasil e Argentina: ditaduras, desaparecimentos e políticas de memória. Porto Alegre: Medianiz, 2012.

BENVENISTE, Emile. O Vocabulário das Instituições Indo-européias. Campinas: Unicamp, 1995. v. 2: Poder, Direito, Religião.

BRASIL. A Anistia na Era da Responsabilização: O Brasil em Perspectiva Internacional e Comparada. Brasília/Oxford: Ministério da Justiça, Comissão de Anistia/Oxford University, Latin America Centre, 2011.

BUTLER, Judith. O parentesco é sempre tido como heterossexual. Cadernos Pagu, v. 21, p. 45-49, 2003.

CIDH. Corte Interamericana de Direitos Humanos. Sentença Caso Gomes Lund e outros (“Guerrilha do Araguaia”) vs. Brasil. 24 nov. 2010. Disponível em: http://www.corteidh.or.cr/docs/casos/articulos/seriec_219_por.pdf. Acesso em: 13 jul. 2019.

DUNKER, Christian. Mal-Estar, Sofrimento e Sintoma: uma psicopatologia do Brasil entre muros. São Paulo: Boitempo, 2015.

FASSIN, Didier; RETCHMAN, Richard. L'empire du traumatisme: Enquête sur la condition de victime. Paris: Champs Essais, 2007.

FERENCZI, Sandor. Deux types de névroses de guerre (hystérie). In: FREUD, Sigmund; FERENCZI, Sandor; ABRAHAM, Karl. Sur les névroses de guerre. Paris: Petite Bibliothèque Payot, 2010 [1916].

INDURSKY, Alexei; KVELLER, Daniel. Anistia, testemunho e reconhecimento. In: Por que uma clínica do testemunho. Porto Alegre: Instituto Appoa, 2018.

KEHL, Maria Rita. Tortura e sintoma social. Correio da APPOA, ed. 196, p. 77-88, 2010.

MUÑOZ, Oscar. Re-trato [Online]. s.d. Disponível em: https://vimeo.com/39354097. Acesso em: 16 abr. 2019.

O SILÊNCIO DOS OUTROS. Direção: CARRACEDO, Almudena; BAHAR, Robert. Espanha: Supo Mungan Films, 2019. (1h35min).

RICOUER, Paul. Le juste. Paris: Éditions Esprit, 1995.

SIRONI, Françoise. Carrascos e vítimas: Psicologia da tortura. São Paulo: Terceira Margem, 2011.

Artigo recebido em: Abril/2019

Artigo aprovado em: Julho/2019 


\begin{abstract}
Alexei Conte Indursky (alexei.indursky@gmail.com) é Doutor em Psicanálise e Psicopatologia pela Université Paris VII - Denis Diderot/França.
\end{abstract}

Daniela Sevegnani Mayorca (ds.mayorca@gmail.com) é Mestre em Psicologia pela Universidade Federal de Minas Gerais (UFMG).

\title{
Clínicas do Testemunho: a política de reparação psíquica no Brasil
}

Resumo. O presente artigo propõe refletir sobre a emergência e implementação da política de reparação psíquica, Clínicas do Testemunho, na agenda de justiça de transição no Brasil. Inicialmente, procuramos realizar um apanhado histórico que demonstrasse as condições de possibilidade dessa política em nosso contexto. Em seguida, justificamos a pertinência da metodologia clínica e política empregada ao longo do projeto, a partir de uma revisão crítica sobre os efeitos sintomáticos da política de perdão, veiculada através da noção de anistia no Brasil. Para tanto, apostamos que uma política de reparação psíquica pressupõe um contexto sócio-político desde o qual são moduladas as próprias bases normativas e os sentidos do que é ser vítima da violência de Estado. Na sequência, serão apresentados os principais efeitos clínicos e políticos produzidos através de vinhetas clínicas. Por fim, será realizada uma discussão dos resultados e os desafios que representam para a agenda da Justiça de transição no Brasil.

Palavras-chave: Reparação Psíquica; Justiça de Transição; Testemunho; Trauma; Violência de Estado.

\section{Clinics of Testimony: the policy of psychic reparation in Brazil}

\begin{abstract}
The present article proposes to reflect on the emergence and implementation of the policy of psychic reparation, Clinics of Testimony, in the agenda of justice of transition in Brazil. Initially, we seek to make a historical overview that demonstrates the conditions of possibility of this policy in our context. Next, we aim to justify the pertinence of the clinical and political methodology employed throughout the project, based on a critical review on the symptomatic effects of the extorted reconciliation, conveyed through the notion of amnesty in Brazil. Therefore, we crave that a policy of psychic reparation presupposes a socio-political context in which the normative bases themselves and the meanings of being a victim of State violence are modulated. Following, the main clinical and political effects produced by the project and clinical vignettes will be presented. Finally, a discussion will be held of the results and the problems they bring to the Transitional Justice agenda in Brazil.

Keywords: Psychic Reparation; Transitional Justice; Testimony; Trauma; State Violence.
\end{abstract}

